\title{
Effect of the Acidic Treatment of Domestic Wood Residue on Biocomposite Wettability and Moisture Sorption Properties
}

\author{
Jevgenijs Jaunslavietis ${ }^{1}$, Galia Shulga ${ }^{1}$, Jurijs Ozolins ${ }^{2}$, Brigita Neiberte ${ }^{1}$, \\ Anrijs Verovkins ${ }^{1}$, Sanita Vitolina ${ }^{1}$, Sandra Livca ${ }^{1}$ \\ ${ }^{1}$ Laboratory of Lignin Chemistry, Latvian State Institute of Wood Chemistry, Riga, Latvia; \\ ${ }^{2}$ Faculty of Materials Science and Applied Chemistry, Riga Technical University, Riga, Latvia.
}

\begin{abstract}
The aim of the work was to evaluate the effect of the acidic treatment temperature of aspen sawdust as a filler on the moisture sorption, wetting and mechanical properties of wood-polymer composites. Aspen wood sawdust was treated with the dilute hydrochloric acid solution at $60^{\circ} \mathrm{C}$ and $90^{\circ} \mathrm{C}$ during $5 \mathrm{~h}$. Both the treated particles and the filled composites were studied in terms of moisture sorption and wettability; their surface free energy was calculated using the Owens-Wendt-Rabel-Kaelble (OWRK) approach. The obtained results have shown that the acidic treatment of aspen wood sawdust at $90^{\circ} \mathrm{C}$ leads to an increase in its hydrophobicity that decreases the wettability and moisture sorption of the obtained composite and increases its mechanical properties.
\end{abstract}

Keywords: Mild Acidic Treatment, Moisture Sorption, Wettability, Wood-Polymer Composite, Wood Residue.

\section{INTRODUCTION}

Wood-polymer composites (WPCs) are of great interest in various applications due to their low density, low equipment abrasiveness, high stiffness and strength, low maintenance requirements, and biodegradability [1-2]. Polyolefins such as polyethylene and polypropylene, the best-known thermoplastics, are often used as a matrix in WPCs. The volume of the produced WPCs increases every year. According to the NOVA-Institute statistical data, 350,000 tons of WPCs were produced in EU in 2015 , but their amount will grow to 450,000 tons in 2020 [3]. Most of the produced WPCs are used for decking (about $67 \%$ ), but $23 \%$ of their total amount are used in the auto industry. The remaining $10 \%$ are used for technical requirements, furniture etc.

Since recycled polymers, the amount of which rapidly grows in the USA, EU and Japan, can be processed below the degradation temperature of wood, they are suitable for producing WPCs. Nowadays, the use of recycled thermoplastics can be considered as a advancing trend for obtaining such a type of composites as decorative and interior building materials. It is very important that the use of recycled synthetic polymers as a polymer matrix in WPCs sufficiently decreases their disposal in landfills, reducing waste volumes, and sufficiently diminishes the pollution of atmosphere, decreasing $\mathrm{CO}_{2}$ emission [4]. At the same time, the incompatibility between hydrophilic lignocelluloses and the hydrophobic polymer matrix leads to a weak adhesion between these ingredients in WPCs. To solve this problem, physical and chemical methods have been used to modify and functionalize the lignocelluloses for increasing their hydrophobicity and improving the interfacial adhesion. Wood functionalization can be realized by various modes, namely, with alkali, benzylation, graft copolymerization, treatment with fatty acids, peroxide, anhydride, permanganate, silane, plasma, etc. $[5,6,7,8,9]$. Acetylation, furfurylation and thermal modification of wood are often used for obtaining WPCs under industrial conditions. To increase the compatibility between the polymer matrix and the lignocellulosic filler, various coupling agents and compatibilizers are also applied in WPC compositions. It is known that maleic anhydride polymer derivatives are often used in practice as interface modifiers, which have a positive effect on the physicochemical properties of WPCs [10-11].

In Latvia, there is a very high amount of wood processing by-products as well as polymer wastes, which could be successfully used as a raw material for the development of new compositions of WPCs.

In this work, hardwood sawdust and recycled polypropylene granules from Latvian wood mechanical and polymer processing companies were used. http://dx.doi.org/10.17770/etr2017vol1.2538 
The aim of the work was to evaluate the effect of acidic treatment temperature on the wetting properties, moisture sorption and surface free energy (SFE) of aspen wood sawdust and to determine the influence of the treated wood particles on the hydrophobic and mechanical properties of the WPC samples.

\section{MATERIALS AND METHODS}

A. Filler

The sawdust represented a by-product of the mechanical processing of aspen wood (Populus tremula). For the valorization, it was treated by acid hydrolysis with $0.1 \%$ hydrochloric acid solution under mild conditions $\left(60^{\circ} \mathrm{C}\right.$ and $90^{\circ} \mathrm{C}, 5 \mathrm{~h}$, mass ratio of wood particles to water $=1 / 20$ ), followed by milling. The fraction less than $100 \mathrm{mkm}$ was used for filling the polymer matrix.

\section{B. Matrix}

For making the WPCs, recycled polypropylene (rPP) $\left(0.9 \mathrm{t} \mathrm{m}^{-3}, 5.2 / 10 \mathrm{~min}\right.$ at $\left.230^{\circ} \mathrm{C}, 2.16 \mathrm{~kg}\right)$ was used as a polymer matrix.

\section{Obtaining Composite Material}

An extruder "Haake MiniLab II" and an injection molding machine "Haake MiniJet II" were used for obtaining composite materials. Filling degree was $50 \%$; processing temperature was $175-180^{\circ} \mathrm{C}$. The extruder screw rotation speed was $130 \mathrm{rpm}$; injection molding pressure was 600-700 bar.

\section{Surface Properties}

To study the surface properties, WPC samples with dimensions of $60 \times 10 \times 1 \mathrm{~mm}$ were prepared. Before testing, the samples were conditioned at $60^{\circ} \mathrm{C}$ for $24 \mathrm{~h}$ and then stored for $1 \mathrm{~h}$ at room temperature in a desiccator with $\mathrm{P}_{2} \mathrm{O}_{5}$.

Contact angles of the hydrolyzed wood particles and the WPC samples were measured with Kruss K100M using Washburn and Wilhelmy methods, respectively. Work of adhesion was calculated using the Young-Dupre equation (1):

$$
\begin{aligned}
& \qquad \mathrm{W}_{\mathrm{A}}=\sigma_{\mathrm{l}}(1+\cos \alpha) \\
& \mathrm{W}_{\mathrm{A}}-\text { work of adhesion }(\mathrm{mN} / \mathrm{m}) \\
& \sigma_{1}-\text { liquid surface tension }(\mathrm{mN} / \mathrm{m}) \\
& \alpha-\text { contact angle (degrees) }
\end{aligned}
$$

The total surface free energy (SFE) and its dispersive (Lifshitz - van der Waals interactions) and polar (Lewis acid-base interactions) components were calculated using the Owens-Wendt-Rabel-Kaelble method [12], for which the contact angle values with different liquids: water, DMSO and diiodomethane were measured. For calculation of SFE, a special software program mounted in Kruss K100M was applied.

Moisture sorption was measured using the desiccator method with $98 \%$ relative humidity.

\section{E. Mechanical Properties}

Mechanical tests were carried out with a universal machine "Zwick" (Zwick/Roell, Germany) with a load capacity of $0.5 \mathrm{kN}$ according to ASTM D638 and EN ISO 178 using a software program TestXpert. Before testing, the samples were conditioned at $60^{\circ} \mathrm{C}$ during $24 \mathrm{~h}$ and then placed in an exicator with phosphorus pentoxide. Five replicates were made for each mechanical testing, and standard deviation for each index was found.

\section{RESULTS AND DISCUSSION \\ A. Aspen Wood Particles}

Table I demonstrates the cellulose, lignin, hemicelluloses content and the oxidation degree $(\mathrm{O} / \mathrm{C}$ ratio) for the initial sample and the samples hydrolyzed at $60^{\circ} \mathrm{C}$ and $90^{\circ} \mathrm{C}$. It can be seen that, with increasing hydrolysis temperature, the content of hemicelluloses in wood particles decreased from $23.4 \%$ at $60^{\circ} \mathrm{C}$ to $19.1 \%$ at $90^{\circ} \mathrm{C}$. Evidently, this was caused by the cleavage of glycoside ether bonds in the hemicelluloses and the release of the degraded fragments into the hydrolyzate. The hemicelluloses content in the hydrolyzate was higher at $60^{\circ} \mathrm{C}$ than at $90^{\circ} \mathrm{C}$. According to Table $\mathrm{I}$, the cellulose relative content increased from $51 \%$ for the initial wood particles to $53.2 \%$ and $54.7 \%$ for the particles hydrolyzed at $60^{\circ} \mathrm{C}$ and $90^{\circ} \mathrm{C}$, respectively. This increase in the relative content of cellulose was associated with decreasing amount of hemicelluloses during the hydrolysis. At the same time, the content of lignin varied insignificantly with increasing temperature to $60^{\circ} \mathrm{C}$. During the acidic treatment at $90^{\circ} \mathrm{C}$, lignin, which is chemically bonded with hemicelluloses, began partly to degrade.

Table I

Component composition of initial and hydrolyzed aspen wood sawdust

\begin{tabular}{|c|c|c|c|c|}
\hline Sample & $\begin{array}{c}\text { Cellulose } \\
(\%)\end{array}$ & $\begin{array}{c}\text { Lignin } \\
(\%)\end{array}$ & $\begin{array}{c}\text { Hemi- } \\
\text { celluloses }(\%)\end{array}$ & $\mathrm{O} / \mathrm{C}$ \\
\hline Initial & $51.0 \pm 1.7$ & $18.5 \pm 1.2$ & $28.3 \pm 1.5$ & 0.937 \\
\hline $\mathbf{6 0}^{\circ} \mathbf{C}$ & $53.2 \pm 1.8$ & $18.5 \pm 1.5$ & $23.4 \pm 1.7$ & 0.958 \\
\hline $\mathbf{9 0}^{\circ} \mathbf{C}$ & $54.7 \pm 1.4$ & $17.9 \pm 1.2$ & $19.1 \pm 1.4$ & 0.949 \\
\hline
\end{tabular}

The decrease in the oxidation degree of the treated wood particles from 0.958 to 0.949 , as the hydrolysis temperature increased from $60^{\circ} \mathrm{C}$ to $90^{\circ} \mathrm{C}$, could be explained by the drop of the hemicelluloses content in the wood particles that promoted the lowering of the surface polarity of the hydrolyzed particles.

Work of adhesion is the work required to separate the surfaces of two different phases. The higher is the work, the harder is to separate two surfaces. The work of adhesion in respect to water was calculated from the values of the measured contact angles, and the obtained results are shown in Fig. 1. It can be seen that the initial aspen wood particles are characterized by the highest work of adhesion, namely, $90.8 \mathrm{mN} / \mathrm{m}$. After the hydrolysis, the work of adhesion of the wood particles hydrolyzed at $60^{\circ} \mathrm{C}$ and $90^{\circ} \mathrm{C}$ decreased by $7.3 \%$ and $10.3 \%$, respectively. This means that the hydrolyzed particles are less 
likely to attract water molecules on their surface in comparison with the initial wood.

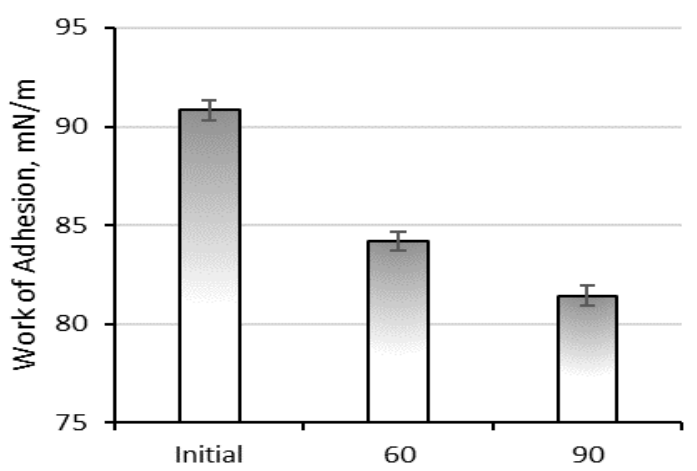

Fig. 1. Work of adhesion with water for the initial wood particles and those hydrolyzed at different temperatures.

The moisture sorption experiment was prolonged for 15 days, and its results are shown in Fig. 2. It is found that, in the first few days, the moisture content of all samples rapidly increased by about $10 \%$, and then the sorption process became slower. The initial aspen wood particles had the highest moisture content, namely, $16.3 \%$, and the particles hydrolyzed at $60^{\circ} \mathrm{C}$ and $90^{\circ} \mathrm{C}$ increased their own masses to a lesser extent, namely, by $15.5 \%$ and $14.7 \%$, respectively. The obtained results on the moisture sorption for the treated particles correlate with the obtained values of the adhesion work.

To better understand the changes in surface properties of the treated wood particles, SFE as well as its dispersive and polar parts were calculated by the Owens-Wendt-Rabel-Kaelble method using for this purpose water, dimethyl sulfoxide and diiodomethane. The obtained results are shown in Fig. 3. It can be seen that the initial wood particles are characterized by an enhanced SFE value, namely, $31 \mathrm{mN} / \mathrm{m}$. After the hydrolysis, SFE for the wood particles treated at $60^{\circ} \mathrm{C}$ and $90^{\circ} \mathrm{C}$ decreased by $22.1 \%$ and $26.6 \%$, respectively. As shown in Fig. 3, the main drop of the SFE values of the particles is associated with the decrease of their SFE polar part, while the SFE dispersive part changes are insignificant (Fig. 3.).

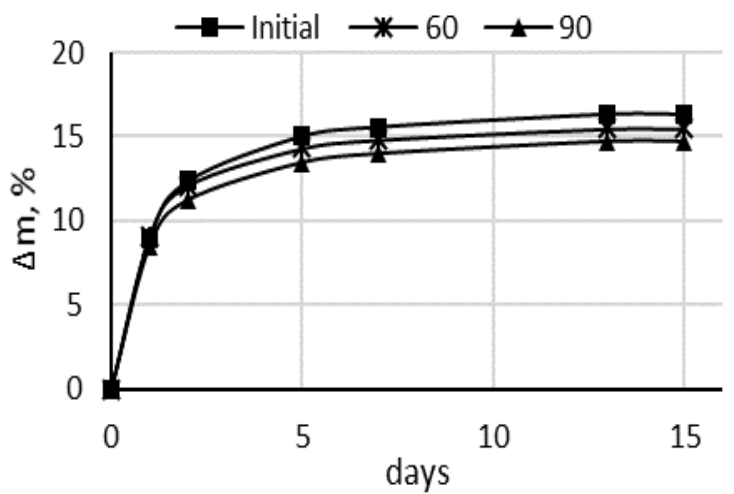

Fig. 2. Moisture sorption of initial aspen wood particles and those hydrolyzed at different temperatures. $\square$ Dispersive part $\quad \square$ Polar part

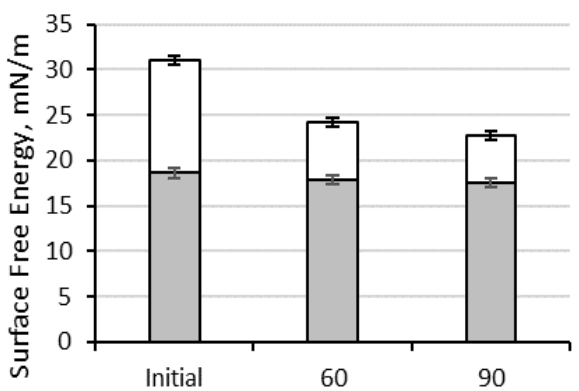

Fig. 3. SFE and its dispersive and polar part of initial and hydrolyzed wood particles.

It can be seen that the wood hydrolysis reduces the SFE polar part from $12.5 \mathrm{mN} / \mathrm{m}$ for the initial particles to $6.3 \mathrm{mN} / \mathrm{m}$ and $5.2 \mathrm{mN} / \mathrm{m}$ for the aspen particles hydrolyzed at $60^{\circ} \mathrm{C}$ and $90^{\circ} \mathrm{C}$, respectively. Such a significant lowering of the SFE polar part indicates the increase in hydrophobicity of the hydrolyzed particles that is more pronounced for the wood particles treated at $90^{\circ} \mathrm{C}$.

\section{Wood-Polymer Composites}

The adhesion work values for the obtained WPC samples with a filling of $50 \%$ are shown in Fig. 4. According to the data, recycled polypropylene has the lowest work of adhesion, namely, $60.8 \mathrm{mN} / \mathrm{m}$, which is associated with a hydrophobic nature of the polymer matrix. The WPC sample containing the initial wood particles has the highest work of adhesion equal to $70.8 \mathrm{mN} / \mathrm{m}$, but for the WPC samples filled with the particles hydrolyzed at $60^{\circ} \mathrm{C}$ and $90^{\circ} \mathrm{C}$, the work of adhesion decreases and is close to $65.3 \mathrm{mN} / \mathrm{m}$ and $64.2 \mathrm{mN} / \mathrm{m}$, respectively.

The moisture sorption experiment was studied during 25 days. According to the results shown in

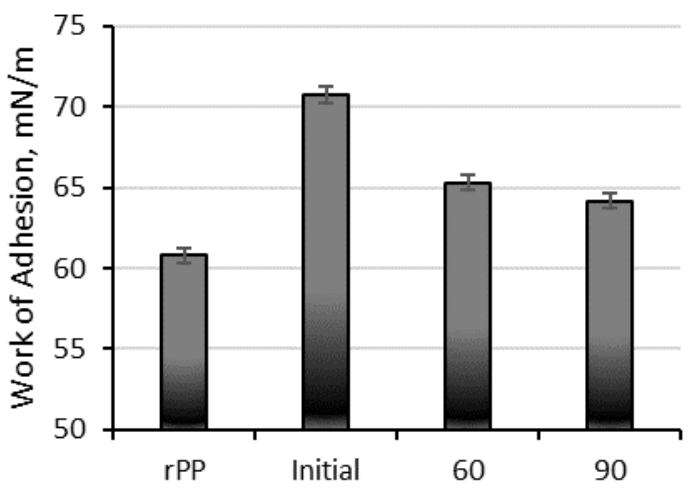

Fig. 4. Work of adhesion of recycled polypropylene (rPP) and WPC with initial and hydrolyzed aspen wood particles.

Fig. 5, the WPC sample filled with the untreated modified wood particles increased its mass by $3.5 \%$ after 25 days of the experiment. The use of the particles hydrolyzed at $60^{\circ} \mathrm{C}$ and $90^{\circ} \mathrm{C}$ as a filler allowed the reduction of the moisture sorption of the WPC samples to $2.9 \%$ and $2.7 \%$, respectively. It can 
be seen that the decrease in the filler moisture sorption leads to the lowering of the moisture sorption of the WPC samples. Fig. 6 illustrates the values of SFE and its dispersive and polar parts of the obtained WPC samples. It can be seen that the SFE values for the WPC samples with the treated wood particles are not changed significantly with temperature and are varied in the range of 26.2-25.4 $\mathrm{mN} / \mathrm{m}$.

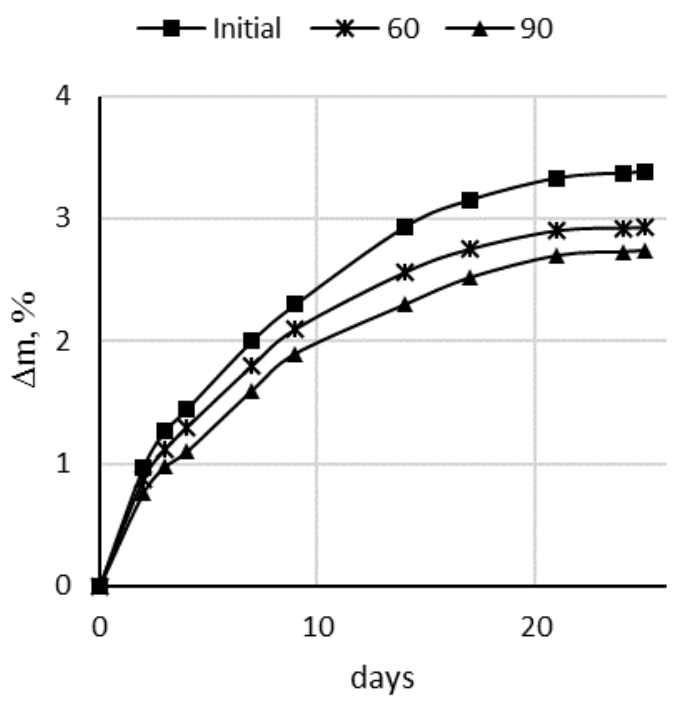

Fig. 5. Moisture sorption of WPCs containing $50 \mathrm{wt} \%$ initial and hydrolyzed aspen wood particles.

Because the WPC sample filled with initial particles has the highest total SFE value, its dispersive part has the lowest value equal to 16.2 $\mathrm{mN} / \mathrm{m}$ that displays the hydrophilic nature of the filler. For the WPC samples containing the hydrolyzed aspen wood particles, the SFE dispersive part grows with increasing hydrolysis temperature. It is characteristic that the treatment at $90^{\circ} \mathrm{C}$ essentially decreases the SFE polar part of the WPC sample containing $50 \%$ of the hydrolyzed particles. This phenomenon could be explained by an increase in the hydrophobicity of the particles, and as a result, a better compatibility between the recycled PP and the wood filler, which, in turn, leads to better mechanical properties of the WPC samples.

Table II

Tensile and Bending properties of WPC

\begin{tabular}{|l|c|c|c|c|c|l|}
\hline \multirow{2}{*}{ Sample } & \multicolumn{3}{|c|}{ Tensile } & \multicolumn{3}{c|}{ Bending } \\
\cline { 2 - 7 } & $\begin{array}{c}\sigma \\
(\mathrm{MPa})\end{array}$ & $\begin{array}{c}\mathrm{E} \\
(\mathrm{MPa})\end{array}$ & $\begin{array}{c}\varepsilon \\
(9 \%)\end{array}$ & $\begin{array}{c}\sigma \\
(\mathrm{MPa})\end{array}$ & $\begin{array}{c}\mathrm{E} \\
(\mathrm{MPa})\end{array}$ & $\begin{array}{l}\varepsilon \\
(\%)\end{array}$ \\
\hline rPP & 20.9 & 495 & 25 & 26.9 & 898 & 9.3 \\
\hline Initial & 21.2 & 590 & 17.5 & 28.5 & 1740 & 5.8 \\
\hline $\mathbf{9 0}$ & 30.2 & 927 & 7.5 & 33.9 & 3210 & 2.1 \\
\hline
\end{tabular}

$\square$ Disperse part $\square$ Polar part

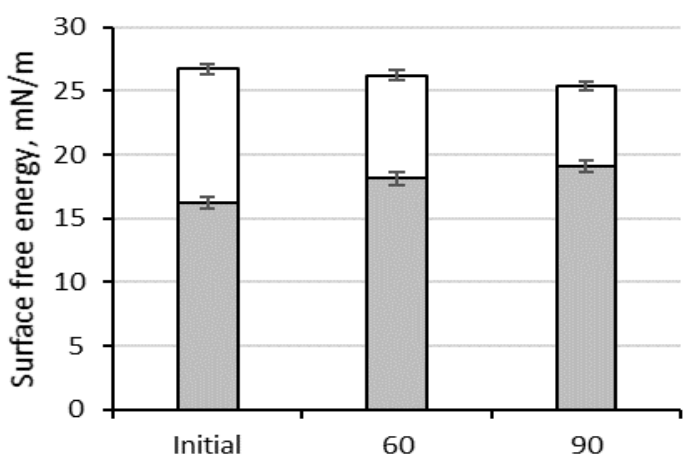

Fig. 6. SFE of the obtained WPC samples.

The studied mechanical properties (tensile and bending) of the obtained WPC samples are shown in Table II. Recycled polypropylene has the lowest values of tensile strength and elasticity modulus as well as the highest elongation. The WPC sample containing the untreated wood particles has the insignificant improvement in the mechanical properties.

At the same time, the WPC sample filled with the wood particles treated at $90^{\circ} \mathrm{C}$ has enhanced values of mechanical strength and modulus as well as the lowest values of deformation. In comparison with the case of the WPC sample filled with untreated wood particles, its tensile and bending strength values increase by $40 \%$ and $19 \%$, respectively, but the deformation decreases 2.3-2.8 times.

The pronounced improvement in the mechanical properties of the WPC sample filled with the wood particles hydrolyzed at $90^{\circ} \mathrm{C}$ could be explained by the decrease of their hydrophilicity that promoted the increase of the interfacial adhesion between the polymer matrix and the lignocellulosic filler.

\section{CONCLUSIONS}

The obtained results have shown that the acidic treatment of aspen wood sawdust at $90^{\circ} \mathrm{C}$ leads to an increase in its hydrophobicity that decreases the wettability and moisture sorption of the obtained wood-polymer composite and increases its mechanical properties.

\section{ACKNOWLEDGEMENTS}

The authors would like to thank the Ministry of Education and Science of the Republic of Latvia for the financial support from the National Research Programme (ResProd) and the basic funding.

\section{REFERENCES}

[1] D. Klemm, B. Heublein, H. P. Fink and A. Bohn, "Cellulose: Fascinating biopolymer and sustainable raw material," Angew. Chem., Int. Ed., vol. 44, 2005, pp. 3358-3393.

[2] A. K. Mohanty, M. Misra and L. T. Drzal, "Sustainable BioComposites from renewable resources: Opportunities and challanges in the green materials world," J. Polym. Environ., vol. 10, 2002, pp. 19-26. 
Environment. Technology. Resources, Rezekne, Latvia Proceedings of the $11^{\text {th }}$ International Scientific and Practical Conference. Volume I, 129-133

[3] M. Carus, A. Eder, L. Dammer, H. Korte, L. Scholz, R. Essel and E. Breitmayer, "Wood plastic composites (WPC) and natural fibre composites (NFC): European and Global markets 2012 and future trends," 2014. [Online]. Available: www.bio-based.eu/markets [Accessed: Feb. 18, 2017].

[4] M. N. Rao, R. Sultana and S. H. Kota, Solid and Hazardous waste management. Joe Hayton, 2017

[5] C. M. Popescu, "A near infrared spectroscopic study of the structural modifications of lime (Tilia CordataMill.) wood during hydro-thermal treatment," Spectrochim. Acta. A. Mol. Biomol. Spectrosc., vol. 115, 2013, pp. 227-233.

[6] J. O. Nwadiogbu, P. A. C. Okoye, V. I. Ajiwe and N. J. N. Nnaji, "Hydrophobic treatment of corn cob by acetylation: Kinetics and thermodynamics studies," J. Environ. Chem. Eng., vol. 2, 2014, pp. 1699-1704

[7] W. Z. W. Zahari, R. N. R. L. Badri, H. Ardyananta, D. Kurniawan and F. M. Nor, "Mechanical Properties and Water Absorption Behavior of Polypropylene / Ijuk Fiber Composite by Using Silane Treatment,” Proc. Manuf., vol. 2, 2015, pp. 573-57.

[8] G. Shulga, J. Jaunslavietis, J. Ozolins, B. Neiberte, A. Verovkins, S. Vitolina and V. Shakels, "Properties of
Recycled Polypropylene Based Composites Incorporating Treated Hardwood Sawdust," AIP Conference Proceedings of the 8th International Conference "Times of Polymers (TOP) \& Composites. From Aerospace to Nanotechnology.” Ed. A. D'Amore, D. Acierno and L.Grassia. vol. 1736, 020111 (2016); http://dx.doi.org/10.1063/1/1/4949686.

[9] G. Shulga, B. Neiberte, A. Verovkins, S. Vitolina, J. Jaunslavietis, J. Ozolins, "Short fibre filler from wood residue for polymer composite materials," Material Science, vol. 22, 2016, pp. 370-375,

[10] W. Deng, Y. Song, Q. Wang and W. Wang, "Improvement of compatibility and mechanical properties of modified wood fiber/polypropylene composites", Frontiers of Foresty in China, vol. 3, 2008, pp. 243-247.

[11] D. Ndiaye and A. Tidjani, "Effects of coupling agents on thermal behaviour and mechanical properties of wood flour/polypropylene composites," J. Composite Materials, vol. 46, no. 24, 2012. pp.3067-3075.

[12] A.W. Adamson and A. P. Gast, Physical Chemistry of Surfaces. New York: John Wiley \& Sons, 1997. 